\title{
Young Ants Already Possess a Mental Number Line
}

\author{
Marie-Claire Cammaerts ${ }^{1} \&$ Roger Cammaerts ${ }^{2}$ \\ ${ }^{1}$ Independent Researcher, Retired from the Biology of Organisms Department, University of Brussels, Belgium \\ ${ }^{2}$ Independent Researcher, Retired from the Natural and Agricultural Environmental Studies Department (DEMNA) \\ of the Walloon Region, Belgium \\ Correspondence: Marie-Claire Cammaerts, Independent Researcher, 27, Square du Castel Fleuri, 1170 Bruxelles, \\ Belgium. Tel: 32-2-673-49-69. E-mail: mccammaerts@gmail.com
}

Received: December 6, 2019

Accepted: January 8, 2020

Online Published: January 16, 2020

doi:10.5539/ijb.v12n2p1

URL: https://doi.org/10.5539/ijb.v12n2p1

\begin{abstract}
The workers of the ant Myrmica sabuleti were previously shown to have a compressed left to right oriented mental number line. It remained to know if they detain this trait soon after their emergence, or if they have to acquire it in the course of their life. We worked on workers a few days to at most 5-6 weeks old, maintained in small artificial nests. We trained them either to a small number of dots versus a larger one, or to a large number versus a smaller one, and tested them in front of twice the small or the large number of dots presented on the left as well as on the right of respectively the larger or the smaller number. The young ants went preferentially to the small number located on the left of the larger one, and to the large number located on the right of the smaller one. Such a left or right preference occurred only in the presence of a larger or a smaller number set between the two small or large presented numbers. Young ants thus mentally locate the small amounts on their left and the larger ones on their right. Their representation of amounts on an oriented line could be native.
\end{abstract}

Keywords: Conditioning, Myrmica sabuleti, Numerosity, Numbers Discrimination, Ontogeny

\section{Introduction}

Humans as well as the few animal species which were studied for this topic were found to possess an oriented mental representation of numerosity or of numbers on a scale. A magnitude system of numerosity discrimination is already present in fishes as the accuracy of swordtails, mosquito fishes and guppies to discriminate between shoals is a function of the latter size ratio, in accordance with Weber's law (Buckingham, Wong, \& Rosenthal, 2007; Agrillo, Dadda, Serena, \& Bisazza, 2008; Agrillo, Piffer, Bisazza, \& Butterworth, 2012), what suggests a numerosity representation in connection with a nonlinearly scaled number line. Research on the subject incites to presume that vertebrates including humans natively possess a number line. For example, newborn domestic chicks already situate the amounts on a left to right oriented number line (Rugani, Rosa-Salva, \& Regolin, 2014; Rugani, Vallortigara, Priftis, \& Regolin, 2015). Rhesus monkeys also spontaneously (i.e. without training) arrange amounts on a scale (Hauser, Carey, \& Hauser, 2000; Flombaum, Junge, \& Hauser, 2005). In humans, associating numerosity and space on a number line appears to be natively detained, the possession of a number line being independent of the kind of reading or writing specific to civilization and education, although the direction of this line (e.g. its left to right orientation or the reverse) is shaped by cultural experience (Göbel, Shaki, \& Fischer, 2011; see also the instructive review of Rugani \& de Hevia, 2017). Later in their life, through learning, humans acquire a more exact, linear and complex number representation (Meyer, 2015), using then symbols for the numbers, and becoming able to make operations without seeing their results, as well as acquiring the notion of zero. More information about the acquisition of a number line in vertebrates will be given in the Discussion section.

It has been previously shown that the workers of the ant Myrmica sabuleti Meinert 1861 also mentally represent amounts on a number line, locating the smaller amounts on the left and the larger ones on the right, and that their accuracy in discriminating between amounts decreases with the increasing size of the latter (Cammaerts \& Cammaerts, 2019, 2020). These experimental works were made on foragers aged of two to three years. It remained to know if these ants acquired their number representation on a left to right oriented line in the course of their first year of life, or if they already detained this mental characteristic soon after their emergence.

For approaching the problem of the number line acquisition in ants, we experimented on very young ants, emerged since a few days to $c a 5-6$ weeks, and maintained in small laboratory nests. We examined if they detain or not a 
number line just as we did for older workers (foragers 2 to 3 years old), but using smaller nest tubes and foraging trays since they were only about twenty in each of the six artificial colonies made and since these young ants only little foraged.

\section{Material and Methods}

\subsection{Collection and Maintenance of Ants}

The experiments were conducted on the young workers of a large colony (containing more than 2,000 workers) of Myrmica sabuleti Meinert 1861 collected in September 2019 in an abandoned stone quarry located at Olloy/Viroin (Ardenne, Belgium). This colony was divided in eleven smaller ones maintained in the laboratory, and from which six small colonies (labeled A to F) containing only 20-23 young workers could be established (Figure 1, left part). These young ants, a few days to $c a 5-6$ weeks old, could easily be recognized by their pale color contrasting with the darker color of older workers. Each of the small colonies was maintained in semi-transparent tubes (diam: 1 $\mathrm{cm}$, length: $7.5 \mathrm{~cm}$ ) half-filled with water, a cotton plug separating the ants from the water, and deposited in a tray $(30 \mathrm{~cm} \times 15 \mathrm{~cm} \times 4 \mathrm{~cm})$ the borders of which having been slightly covered with talc to prevent ants from escaping (Figure 1, right part). The trays served as foraging area, food being delivered in them. The ants were also trained in these trays (Figure 2, left part). Food consisted in a solution of honey in milk $(20 \%$, V/V) delivered in cotton plugged tubes (diam: $0.5 \mathrm{~cm}$, length: $2.5 \mathrm{~cm}$ ) permanently present in the ants' tray and renewed every seven days. Natural lighting was provided by a window what allowed having $c a 9: 15 \mathrm{~h}$ light-dark periods. While caring of the ants and experimenting them, artificial lighting was produced by a Philips TLD $30 \mathrm{~W} / 33$ white light tube, with an intensity of 330lux. The room temperature equaled $20^{\circ} \pm 1^{\circ} \mathrm{C}$, the ambient humidity $80 \%$, and the electromagnetic field $2 \mu \mathrm{W} / \mathrm{m}^{2}$. These environmental conditions were optimum for the maintained species.

\subsection{Training the Ants}

At a given time, a stand with a number of green circles (see below the setting of this cue) was deposited near the ants' food and another stand with a larger or smaller number of green circles was deposited far from the food (Figure 2, left part). Doing so, the ants underwent through operant conditioning: they were expected to learn and memorize the number of circles deposited near the food and to neglect the number of circles deposited far from the food. The numbers of ants present in the vicinity of the two presented numbers of circles were counted four times each day over three days, and the mean of these counts was established after two days, then after one more day (Table 1, second column). The ants were tested after two, then after three training days (see below).

\subsection{Testing the Ants}

The ants were tested in a separate tray $(15 \mathrm{~cm} \times 7 \mathrm{~cm} \times 4.5 \mathrm{~cm})$ the borders of which having been covered with talc and into which three stands bearing each a number of green circles had been deposited (Figure 2, right part). The number of circles the ants were expected to learn was presented twice, i.e. on the left as well as on the right of the number the ants were expected to avoid and which was deposited between the two presented numbers of circles expected to be memorized. After two then three training days, for testing, the trained young workers of a colony were transported into the tray devoted to test, and those approaching each presented number of circles were counted 20 times over 10 minutes. The mean of these counts was established for each kind of presented numbers of circles (Table 1, third column).

The trays devoted to testing were differently oriented over the successive testing sessions performed in order to avoid any impact of the direction of the light on the ants' choice of cues.

On the basis of the obtained results, it was estimated that a supplementary experiment should be conducted as a checking. During the testing session of this checking experiment, the stand corresponding to that set far from the food during training, and bearing the number of circles to avoid, was not set between the two identical stands bearing the numbers to which the ants were conditioned.

\subsection{Cues Presented to the Ants}

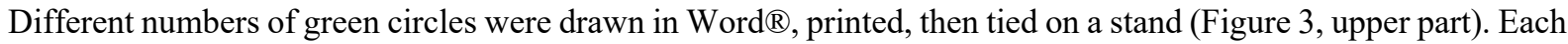
stand had a vertical part $(2 \mathrm{~cm} \times 2 \mathrm{~cm})$ and a base $[2 \times(0.5 \mathrm{~cm} \times 1 \mathrm{~cm})]$ duly folded to allow its vertical maintenance. Distinct stands and printed numbers were used for training and testing.

The numbers of tied green circles differed according to the conducted experiment (Figure 3, lower part). For experiment I made on colony A, a stand with 1 green circle was set near the food and a stand with 3 circles was set far from the food during training, while for testing a stand with 1 circle was set on the left as well as on the right of a stand with 3 circles. For experiment II made on colony B, a stand with 2 green circles was set near the food and a stand with 4 circles was set far from the food during training, while for testing a stand with 2 circles 
was set on the left as well as on the right of a stand with 4 circles. For experiment III made on colony C, a stand with 3 green circles was set near the food and a stand with 5 circles was set far from the food during training, while for testing a stand with 3 circles was set on the left as well as on the right of a stand with 5 circles. For experiment IV made on colony D, a stand with 3 green circles was set near the food and a stand with 1 circle was set far from the food during training, while for testing a stand with 3 circles was set on the left as well as on the right of a stand with 1 circle. For experiment V made on colony E, a stand with 4 green circles was set near the food and a stand with 2 circles was set far from the food during training, while for testing a stand with 4 circles was set on the left as well as on the right of a stand with 2 circles. For experiment VI made on colony F, a stand with 5 green circles was set near the food and a stand with 3 circles was set far from the food during training, while for testing a stand with 5 circles was set on the left as well as on the right of a stand with 3 circles. Briefly, during experiments I, II, III, a small number was expected to be learned during training and was presented on the left and on the right of a larger number during testing. Inversely, during experiments IV, V, VI, a large number was expected to be learned during training and was presented on the left and on the right of a smaller number during testing.

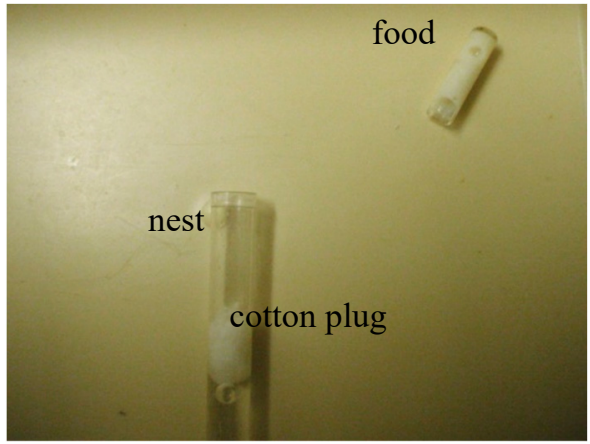

A

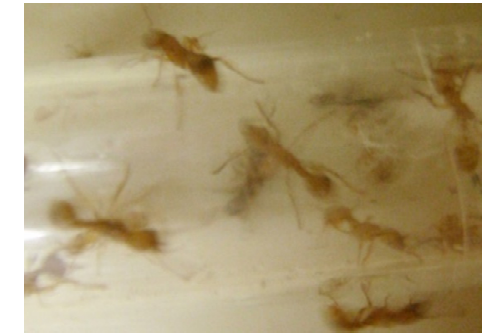

B

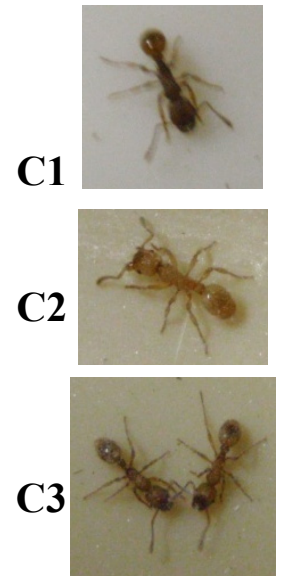

Figure 1. Workers used in the present work

A: young workers were maintained in small tubes half filled with water, and fed with a $20 \% \mathrm{~V} / \mathrm{V}$ solution of honey in milk delivered in a very small tube. B: young workers as seen through the semi-transparent tube serving as a nest. C1: an old dark worker of the collected colony. C2: a pale, very young worker, just emerged, used for the experiments. C3: young workers, emerged a few days ago and also used for the experiments.

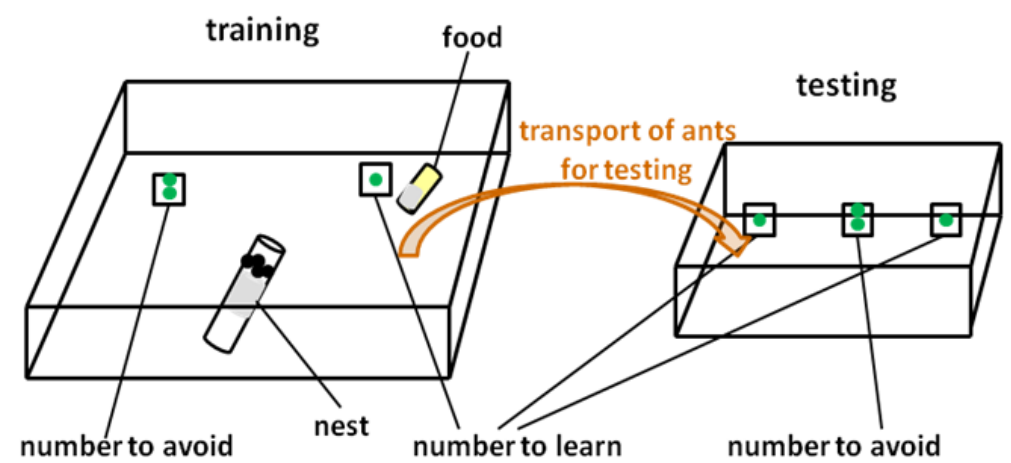

Figure 2. Experimental design

Left: young ants were trained on their foraging area; a number of green circles was set near the food and another, larger or smaller number of such circles was set far from the food. Right: the young ants were tested in a separate tray with the number of circles set far from the food presented in the middle and the number of circles set near the food presented on the left as well as on the right of the number of circles previously set far from the food. The visual cues used for testing were identical to those used for training, but were new, never used. 


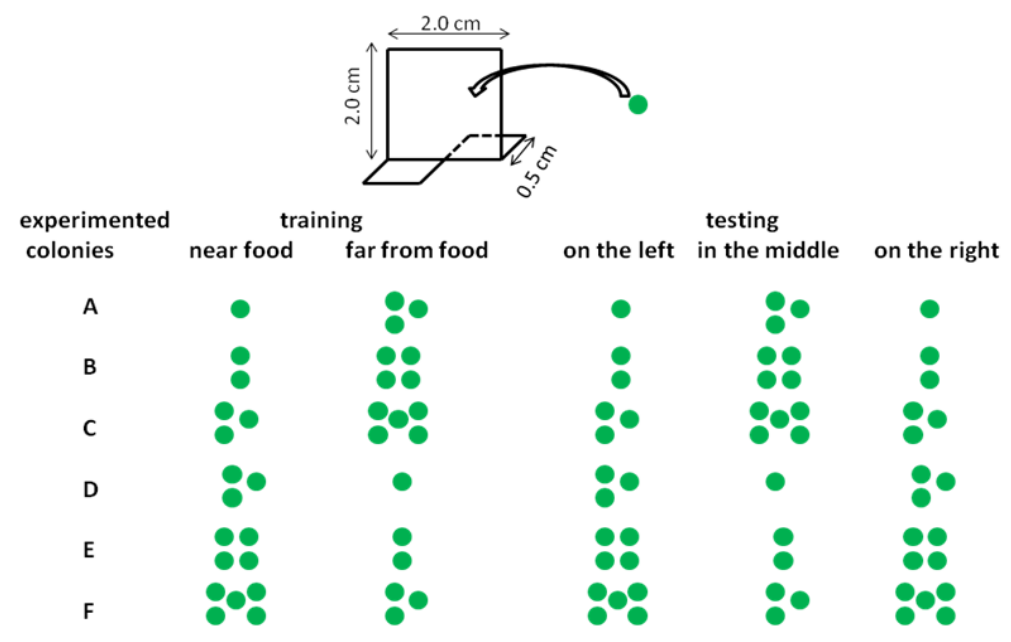

Figure 3. Cues presented to the ants

Upper part: the numbers of green circles used for experimenting were drawn on a piece of paper $(2 \mathrm{~cm} \times 2 \mathrm{~cm})$ tied to the front face of a stand which was presented to the ants. Lower part: each colony was trained to a number of green circles set near the food $v s$ a larger (for colonies A, B, C) or smaller (for colonies D, E, F) number of such circles set far from the food; the ants were tested in front of the number of circles set near the food presented on the left and of the right of the number of circles set far from the food.

\subsection{Statistical Analysis of the Ants' Responses}

The numbers of ants recorded during training did not require statistical analysis.

The values recorded during testing required statistical analysis. For each experiment, the twenty chronologically recorded numbers of ants approaching each stand were arranged and summed by four and the series of five sums obtained for each stand were compared using the non-parametric test of Wilcoxon (Siegel \& Castellan, 1989), with 0.05 as probability level.

\section{Results}

\subsection{Synopsis}

We relate firstly the results of the experiments during the training session of which the ants had a smaller number of circles near their food and a larger number of circles far from the food, these numbers being successively $1 \mathrm{vs}$ $3,2 v s 4,3$ vs 5 . Then we give the results of the checking experiment the testing session of which was conducted in the absence of the larger number of circles. The means of these numerical results are given in the upper part of Table 1, and photos of the experiments are shown in Figure 4.

Secondly, we relate the results of the experiments during the training session of which the ants had a larger number of circles near their food and a smaller number of circles far from the food, these numbers being successively $3 v s$ $1,4 v s 2,5 v s$. We end this second part by giving the results of the checking experiment the testing session of which was conducted in the absence of the smaller number of circles. The means of these numerical results are given in the lower part of Table 1, and photos of the experiments are shown in Figure 5.

\subsection{Experiment I, Colony A, Conditioning to 1 Circle vs 3 Circles}

During their training, meanly 2.1 ants of colony A were seen at any time all around the two presented cues. After two training days, during their testing, these young ants went preferentially towards the 1 circle located on the left of the 3 circles. Meanly 3.1 ants were counted there while 0.8 ants were counted near the 3 circles as well as near the 1 circle located on the right of the 3 circles. Summed by four over the twenty counts, the numbers of ants sighted near the 1 circle located on the left were 14, 14,13,13, 7, the numbers of ants sighted near the 3 circles were $2,6,4,2,2$, and those of ants sighted near the 1 circle located on the right were 4, 4, 3, 4, 0 . The first of these three series of values statistically differed from the two others $(\mathrm{N}=5, \mathrm{~T}=15, \mathrm{P}=0.031)$, while the latter did not statistically differ from one another $(\mathrm{N}=5, \mathrm{~T}=+7,-8, \mathrm{P}=0.50)$. The young ants reacted thus significantly more to 1 circle located on the left of the 3 circles than to 3 circles and to 1 circle located on the right. After three training days, the tested young ants once more went mostly to 1 circle set on the left of the 3 circles (while the tray devoted to testing had been turned $180^{\circ}$ ). Meanly, 2.4 ants have been counted near the left stand with 1 circle while 0.7 
and 0.6 ants were counted near the stand with 1 circle set on the right and near the middle stand with 3 circles respectively. Summed by four over the twenty counts, the numbers of ants approaching the 1 circle located on the left were $10,8,9,9,12$, those of ants approaching the 3 circles were $4,0,3,0,4$, and those of ants approaching the 1 circle set on the right were $1,1,4,3,1$. The first of these three series statistically differed from the two other ones $(\mathrm{N}=5, \mathrm{~T}=15, \mathrm{P}=0.031)$. The two other series did not statistically differ $(\mathrm{N}=4, \mathrm{~T}=+3.5,-6.5, \mathrm{P}=0.375)$. It can thus be concluded that very young ants conditioned to 1 element, and tested in front of that element set on the left and on the right of 3 elements, significantly reacted mostly to the 1 element present on the left.

\subsection{Experiment II, Colony B, Conditioning to 2 Circles vs 4 Circles}

During their training, young ants of colony B were at any time present in the vicinity of the presented cues, meanly 3.1 being there. After having been trained during two days, these ants went mostly to the 2 circles located on the left of the 4 circles. Meanly 2.4 ants were counted near these 2 circles while 0.8 and 0.6 ants respectively were counted near the 4 circles and the 2 circles located on the right of the 4 circles. Summed by four over the twenty counts, the numbers of ants sighted near the left located 2 circles were $10,8,8,10,12$, sighted near the 4 circles were 2, 2, 3, 4, 4, and sighted near the right located 2 circles were 2, 2, 2, 2, 4. The first of these three series of values statistically differed from the two last ones $(\mathrm{N}=5, \mathrm{~T}=15, \mathrm{P}=0.031)$, and these two last ones were similar $(\mathrm{N}=2, \mathrm{NS})$. The young ants reacted thus essentially to the 2 circles located on the left of the 4 circles. Tested after three training days, in front of the three visual cues $180^{\circ}$ rotated, the same ants went again essentially to the 2 circles located on the left of the 4 circles, and at a lower extend to the two circles located on the right. Meanly, they were 3.2 to approach the left located 2 circles, 0.8 to approach the right 2 circles, and 0.3 to approach the 4 circles. Summed by four over the twenty counts, the numbers of ants counted near the left located 2 circles were $9,13,17,14,10$, those of ants counted near the right located 2 circles were $4,5,4,2,0$, and of ants counted near the 4 circles were $2,0,1,3,0$. The first series statistically differed from the two other ones $(\mathrm{N}=5, \mathrm{~T}=15, \mathrm{P}=$ $0.031)$ which differed from one another but not significantly $(\mathrm{N}=4, \mathrm{~T}=-9,+1, \mathrm{P}=0.125)$. The young ants trained to 2 circles reacted thus to that number of circles, and statistically more to that number of circles located on the left of 4 circles than to that located on the right.

\subsection{Experiment III, Colony C, Conditioning to 3 Circles vs 5 Circles + Checking Experiment}

During training, the young ants of the small colony $\mathrm{C}$ were numerous enough for perceiving the two presented cues, being meanly 3.0 there at any time. Tested after two training days, these ants went essentially to the 3 circles located on the left of the 5 circles (meanly 3.2 ants), less to the 3 circles located on the right of the 5 circles (meanly 0.7 ants), and far less to the 5 circles (meanly 0.4 ants). Summed by four over the twenty counts, the numbers of ants which approached the left 3 circles were 14, 14, 14,11,11, those which approached the right 3 circles were $2,3,3,2,4$, and those which approached the 5 circles were $4,1,2,0,1$. The first series of values statistically differed from the two other ones $(\mathrm{N}=5, \mathrm{~T}=15, \mathrm{P}=0.031)$. The two last series differed from one another, but not significantly $(\mathrm{N}=5, \mathrm{~T}=+3,-12, \mathrm{P}=0.156)$. Consequently, the young ants reacted more to 3 circles than to 5 circles, and more to the left located 3 circles than to the right located 3 circles. Tested after three training days, these ants went again mostly to the 3 circles located on the left of the 5 circles though the three presented cues have been rotated $180^{\circ}$. Meanly 2.8 ants were counted in front of these 3 circles while 0.8 ants and 0.1 ants were counted in front of the 3 circles located on the right of the 5 circles and in front of the 5 circles. Summed by four over the twenty counts, the numbers of ants sighted near the left located 3 circles were 16, 14, 10,8,8, those of ants sighted near the right 3 circles were $4,5,3,3,0$, and of ants sighted near the 5 circles were $2,3,1,2,3$. The first of these three series of values statistically differed from the two other ones $(\mathrm{N}=5, \mathrm{~T}=15, \mathrm{P}=0.031)$ while these two other series, though differing, did not significantly differed $(\mathrm{N}=5, \mathrm{~T}=10, \mathrm{P}=0.313)$. Consequently, the ants reacted more to 3 circles than to 5 circles, and more to the 3 circles located on the left of the 5 circles than to those located on the right.

A checking test experiment was made in the absence of the 5 circles set in the middle, and was made twice, one time with the cues in their initial position, a second time with the cues $180^{\circ}$ rotated. During the first checking experiment, the ants went equally to the left and the right 3 circles, being meanly 1.2 and 1.4 in doing so respectively. Summed by four over the twenty counts, the numbers of ants approaching the left 3 circles were 6 , $5,3,5,5$, and approaching the right 3 circles were $5,5,4,6,7$. These two series of values did not statistically differ $(\mathrm{N}=4, \mathrm{~T}=-2,+8, \mathrm{P}=0.188)$. During the second checking experiment, the ants went slightly more to the right 3 circles than to the left one, being meanly 2.0 and 1.5 respectively in doing so. Summed by four over the twenty counts, the numbers of ants approaching the right 3 circles were 11, 9, 6, 9, 5, and approaching the left 3 circles were $9,6,4,5,5$, the two series differing at the limit of significance $(\mathrm{N}=4, \mathrm{~T}=10, \mathrm{P}=0.063)$. Consequently, in the absence of 5 circles set between two stands with 3 circles, the ants did not go preferentially to the left 3 circles. 
They thus reacted essentially to the left located 3 circles only in the presence of a stand with 5 circles between the two stands with 3 circles.

Table 1. Results of six experiments made on small colonies made of young ants in order to establish if they have a mental left to right oriented number line, i.e. if they locate the smaller amounts on their left and the larger ones on their right

\begin{tabular}{|c|c|c|c|c|}
\hline \multirow{2}{*}{$\begin{array}{c}\text { Colony, days (d), } \mathbf{n}^{\circ} \text { of circles } \\
\text { A, d } 2,1 \text { vs } 3\end{array}$} & \multirow{2}{*}{$\begin{array}{c}\text { Training: mean } \mathbf{n}^{\circ} \text { of ants near the cues } \\
2.0\end{array}$} & \multicolumn{3}{|c|}{$\begin{array}{l}\text { Testing: mean } n^{\circ} \text { of ants approaching the number set } \\
\text { on the left } \quad \text { in the middle on the right }\end{array}$} \\
\hline & & $3.1(61)$ & $0.8(16)$ & $0.8(15)$ \\
\hline d 3 & 2.2 & $2.4(48)$ & $0.6(11)$ & $0.7(13)$ \\
\hline $\mathrm{B}, \mathrm{d} 2,2$ vs 4 & 2.9 & $2.4(48)$ & $0.8(15)$ & $0.6(12)$ \\
\hline d 3 & 3.3 & $3.2(63)$ & $0.3(6)$ & $0.8(15)$ \\
\hline $\mathrm{C}, \mathrm{d} 2,3$ vs 5 & 3.5 & $3.2(64)$ & $0.4(8)$ & $0.7(14)$ \\
\hline $\mathrm{d} 3$ & 2.5 & $2.8(56)$ & $0.1(11)$ & $0.8(15)$ \\
\hline \multirow{2}{*}{$\mathrm{C}$, checking experiment } & & $1.2(24)$ & & $1.4(27)$ \\
\hline & & $1.5(29)$ & & $2.0(40)$ \\
\hline $\mathrm{D}, \mathrm{d} 2,3$ vs 1 & 3.5 & $0.5(10)$ & $0.7(14)$ & $3.5(69)$ \\
\hline d 3 & 2.5 & $0.7(14)$ & $0.4(7)$ & $3.6(72)$ \\
\hline $\mathrm{E}, \mathrm{d} 2,4$ vs 2 & 3.5 & $0.5(10)$ & $0.4(20)$ & $2.8(55)$ \\
\hline d 3 & 2.7 & $0.6(12)$ & $0.2(3)$ & $3.0(59)$ \\
\hline $\mathrm{F}, \mathrm{d} 2,5$ vs 3 & 3.3 & $0.5(10)$ & $0.6(12)$ & $2.8(55)$ \\
\hline $\mathrm{d} 3$ & 1.5 & $0.9(17)$ & $0.1(1)$ & $3.5(70)$ \\
\hline \multirow[t]{2}{*}{$\mathrm{F}$, checking experiment } & & $1.7(34)$ & & $1.5(29)$ \\
\hline & & $1.9(37)$ & & $1.7(34)$ \\
\hline
\end{tabular}

The ants were trained to a small number of circles set near their food $v s$ a larger number set far from food (colonies A, B , C) or to a large number of circles set near the food $v s$ a smaller number set far from food (colonies C, D, E). When tested, the ants went mostly to the small number located on the left of the larger one, and to the large number located on the right of the smaller one. They thus mentally represent the small amounts on the left and the larger ones on the right of an oriented number scale. The numbers in brackets refer to those of ants having approached the stand.

\subsection{Experiment IV, Colony D, Conditioning to 3 Circles vs 1 Circle}

During their training, the ants of colony D could sufficiently perceive the two presented cues being meanly 3.9 at any time in their vicinity. When tested after two training days, these ants went essentially to the 3 circles located on the right of the 1 circle. They were meanly 3.5 in doing so, while meanly 0.5 ants and 0.7 ants respectively went to the 3 circles located on the left of the 1 circle and to the latter. Summed by four over the twenty recorded numbers, the numbers of ants which approached the right located 3 circles were 16,12,15,16,10, those of ants which approached the left located 3 circles were 4, 3, 0, 1,2, and those of ants approaching the 1 circle were 4, 3 , $4,3,0$. The series corresponding to the 3 circles located on the right statistically differed from the two other ones $(\mathrm{N}=5, \mathrm{~T}=15, \mathrm{P}=0.031)$ which did not significantly differed between them $(\mathrm{N}=3, \mathrm{NS})$. The ants reacted thus mostly to the 3 circles located on the right of the 1 circle. When tested again the following day in front of the same cues rotated $180^{\circ}$, the young ants once more went essentially to the 3 circles located on the right of the 1 circle. Meanly 3.6 ants were counted near those 3 circles, while 0.4 ants and 0.7 ants were counted near the 1 circle located in the middle and the 3 circles set on the left. Summed by four over the twenty counts, the numbers of ants sighted near the 3 circles set on the right were $19,16,17,9,11$, those sighted near the 1 circle were $0,0,2,2,3$, and those sighted near the left located 3 circles were $3,3,2,2,4$. The first series of values statistically differed from the second and the third ones $(\mathrm{N}=5, \mathrm{~T}=15, \mathrm{P}=0.031)$, the two last ones not significantly differing $(\mathrm{N}=3$, NS). The ants reacted thus mostly to the 3 circles located on the right of the 1 circle.

\subsection{Experiment V, Colony E, Conditioning to 4 Circles vs 2 Circles}

During their training, a few young ants of colony E were present at any time in the vicinity of the two presented cues, meanly 3.1 being motionless or moving on that area. When tested after two training days, these young ants approached mostly the 4 circles set on the right of the 2 circles, being meanly 2.8 in doing so, while 0.5 and 0.4 ants respectively approached the 4 circles set on the left of the 2 circles and the 2 circles. Summed by four over the twenty counts, the numbers of ants counted in front of the right located 4 circles were 17, 8,11,9, 10, those of 
ants counted in front of the 2 circles were $3,0,0,2,3$, and those of ants counted in front of the left 4 circles were $4,1,0,2,3$. The first series of values statistically differed from the second and the third ones $(\mathrm{N}=5, \mathrm{~T}=15, \mathrm{P}=$ 0.031). The two latter series did not statistically differ $(\mathrm{N}=2, \mathrm{NS})$. The ants reacted thus effectively mostly to the 4 circles set on the right of the 2 circles. When tested after three training days in front of the $180^{\circ}$ rotated three cues, the same ants reacted mostly to the 4 circles set on the right of the 2 circles and, at a far lower extend, to the 4 circles set on the left of the 2 circles. They poorly reacted to the 2 circles. Meanly, 3.0 ants were counted in front of the right 4 circles, 0.6 in front of the left 4 circles, and 0.2 in front of the 2 circles. Summed by four over the twenty counts, the numbers of ants having reacted to the right located 4 circles were $12,16,11,10,10$, those having reacted to the left located 4 circles were $2,3,3,2,2$, and those having reacted to the 2 circles were $0,2,1$, 0,0 . The first of these series of values statistically differed from the two others $(\mathrm{N}=5, \mathrm{~T}=15, \mathrm{P}=0.031)$, the two last series significantly differing from one another $(\mathrm{N}=5, \mathrm{~T}=15, \mathrm{P}=0.031)$. Consequently, the ants trained to 4 circles vs 2 circles responded more to the 4 circles than to the 2 circles, and largely more to the 4 circles located on the right of the 2 circles.
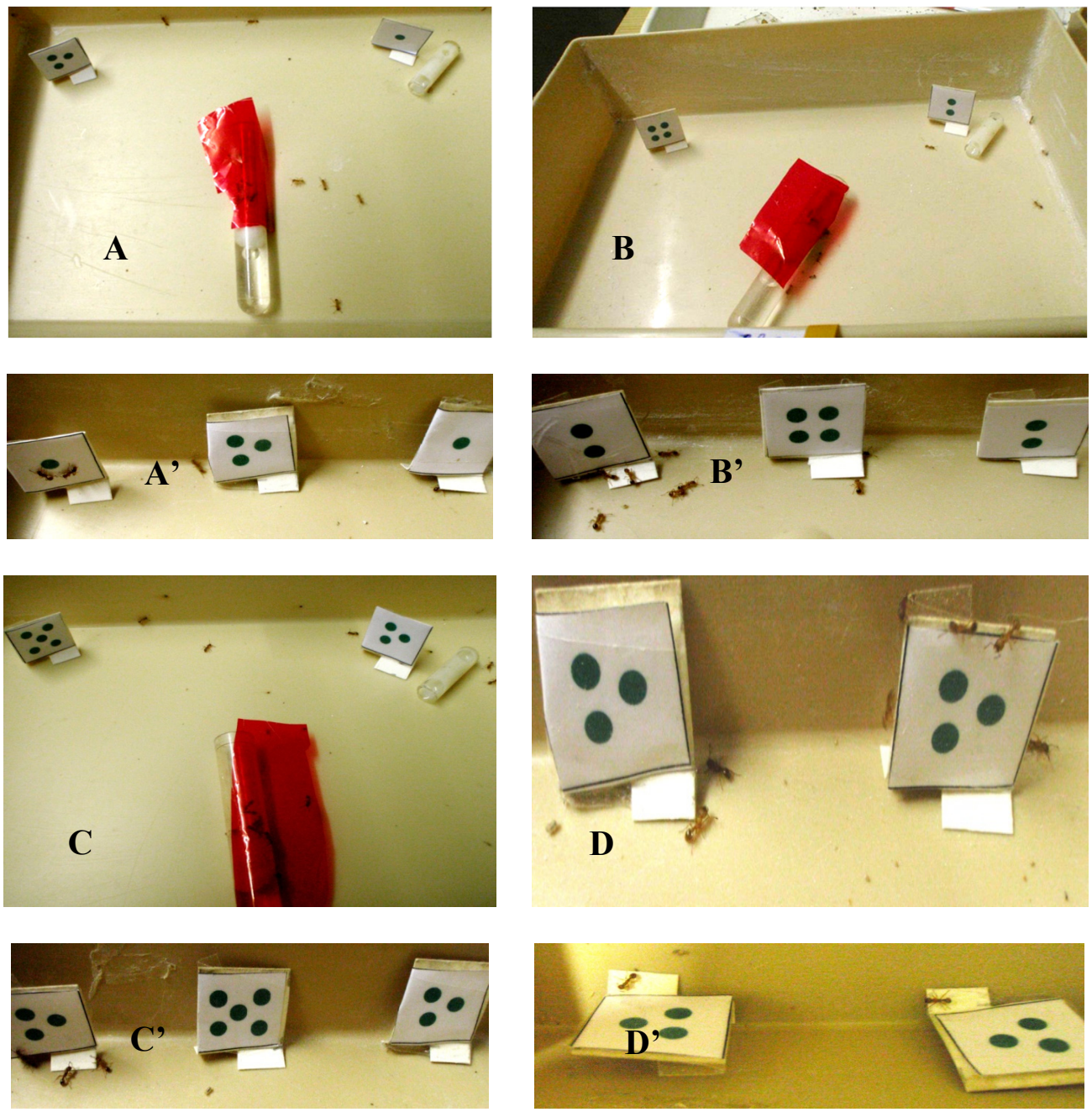

Figure 4. Some views of the experiments I, II, III

A, A': trained to 1 circle set near the food $v s 3$ ones set far from it, the tested ants went essentially to the left 1 circle. B, B': trained to 2 circles set near the food $v s 4$ ones set far from it, the tested ants went mostly to the left 2 circles. C, C': trained to 3 circles set near the food $v s 5$ ones set far from it, the tested ants went mostly to the left 3 circles. D, D': a checking experiment showed that ants went essentially to the left smaller number of circles only in the presence of a larger number of circles between the two presented smaller numbers. These two last photos show that the tray used for testing was $180^{\circ}$ rotated between the test made at day 2 and that made at day 3 (see Table 1). All the experiments were conducted doing such a rotation. 


\subsection{Experiment VI, Colony F, Conditioning to 5 Circles vs 3 Circles + Checking Experiment}

While being trained, the young ants of colony F perceived the two presented cues, being meanly 2.4 staying or moving in their vicinity. Tested after two training days, these ants went preferentially to the 5 circles set on the right of the 3 circles. They were meanly 2.8 in doing so while they were 0.5 and 0.6 respectively in going to the 5 circles set on the left of the 3 circles and to the 3 circles. Summed by four over the twenty recorded numbers, the numbers of ants sighted near the right located 5 circles were $14,10,8,10,13$, those sighted near the left located 5 circles were 2, 2, 3, 1,2, and those sighted near the left 5 circles were $2,2,2,3,3$. The first series of these three ones statistically differed from the two others $(\mathrm{N}=5, \mathrm{~T}=15, \mathrm{P}=0.031)$ and the two latter series did not significantly differ $(\mathrm{N}=3, \mathrm{NS})$. The young ants reacted thus mostly to the 5 circles located on the right of the 3 circles. When tested after three training days in front of the three same cues rotated $180^{\circ}$, the ants again approached mostly the 5 circles located on the right of the 3 circles. They were meanly 3.5 in doing so, while they were 0.9 and 0.1 to approach the 5 circles located on the left of the 3 circles and to approach the 3 circles. Summed by four over the twenty counts, the numbers of ants sighted near the right located 5 circles were $12,15,15,13,15$, those of ants sighted near the left 5 circles were 1, 4, 4, 4, 4, while $0,0,0,0,1$ ants were sighted near the 3 circles. The first of these three series statistically differed from the two other ones $(\mathrm{N}=5, \mathrm{~T}=15, \mathrm{P}=0.031)$, the latter ones significantly differing from one another $(\mathrm{N}=5, \mathrm{~T}=15, \mathrm{P}=0.031)$. The ants reacted thus more to the 5 circles than to the 3 circles, and more to the 5 circles located on the right than to the 5 circles located on the left.
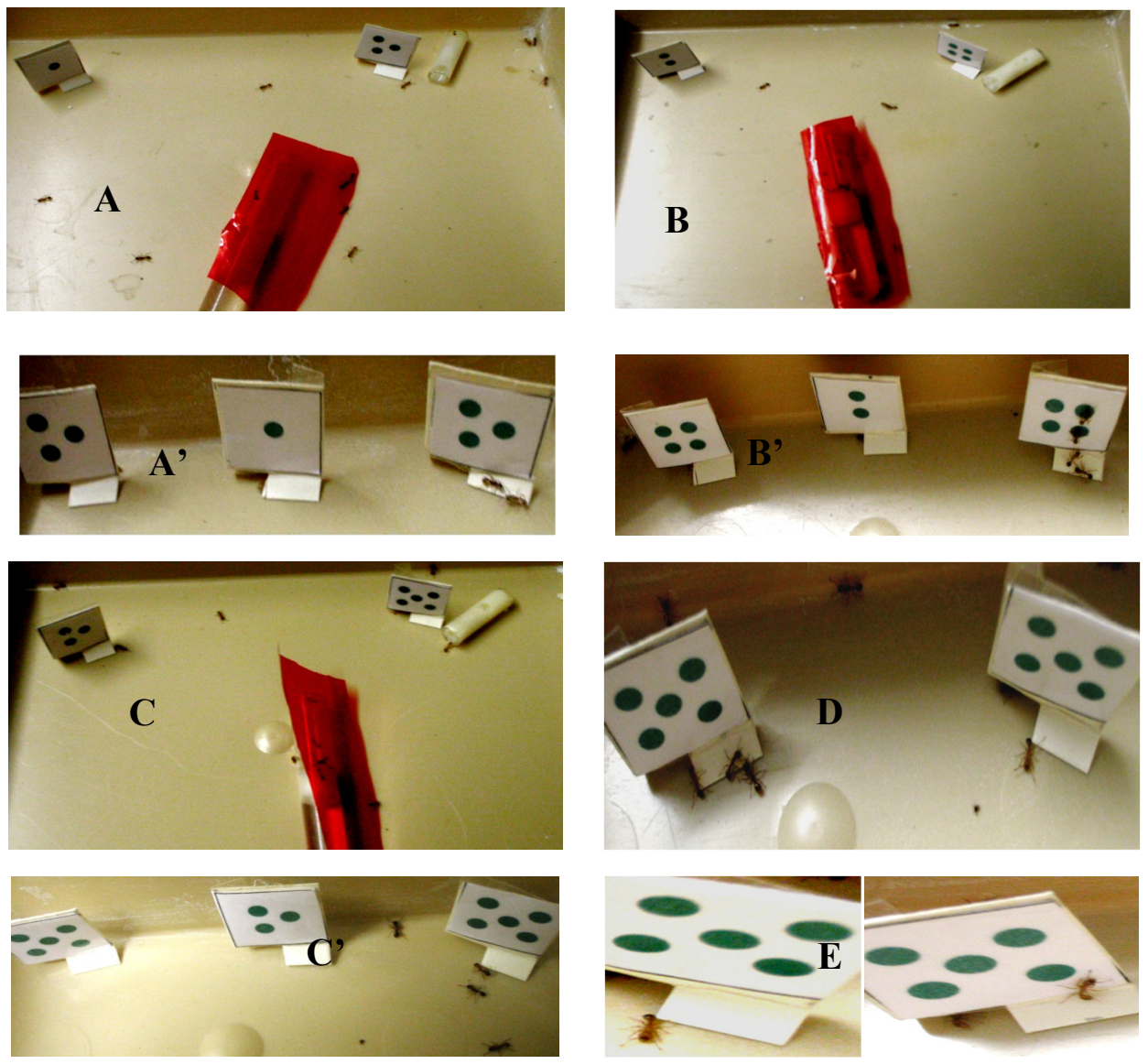

Figure 5. Some views of the experiments IV, V, and VI

A, $\mathbf{A}^{\prime}$ : trained to 3 circles set near the food $v s 1$ set far from it, the tested ants went essentially to the right 3 circles. B, B': trained to 4 circles set near the food vs 2 ones set far from it, the tested ants went mostly to the right 4 circles. C, C': trained to 5 circles set near the food vs 3 ones set far from it, the tested ants went mostly to the right 5 circles. D: a checking experiment showed that ants went essentially to the right larger number of circles only in the presence of a smaller number of circles between the two presented larger numbers. E: two photos for showing that, until the end of the entire experimental work, the used ants were still young. 
A testing session devoted to checking was conducted twice without the stand bearing 3 circles set between the two stands with 5 circles. The tested ants went nearly equally to the two stands bearing 5 circles: they were meanly 1.7 and 1.5 near each of these stands. Summed by four, the numbers of ants approaching the left 5 circles were 11, 6 , $5,5,7$ and those approaching the right 5 circles were $9,6,4,5,5$. These two series did not statistically differ $(\mathrm{N}=$ 3 , NS). During the second checking experiment, meanly 1.7 and 1.9 ants were counted in front of the 5 circles located on the right and the left respectively. Summed by four, the numbers of ants sighted near the right 5 circles were $6,7,6,8,7$, and those sighted near the left 5 circles were $8,5,10,7,7$. These two series did not statistically differ $(\mathrm{N}=4, \mathrm{~T}=-3.5,+6.5, \mathrm{P}=0.375)$. Consequently, the ants went mostly to the larger number of circles set on the right only in presence of a smaller number of circles set between the left and the right located larger number.

\section{Discussion - Conclusion}

Having precedingly shown that the workers of the ant $M$. sabuleti possess a left to right oriented number line (Cammaerts \& Cammaerts, 2019), we aimed to know if such a number representation was present early in their life or if they had to acquire it thanks to learning, by a progressive mental construction through experiences. We worked on young ants, of a few days or at the most 5-6 weeks old. We conditioned them to either a small number of elements $v s$ a larger one, or to a large number of elements $v s$ a smaller one, and tested them in front of twice the conditional number, one on the left and one on the right of the non-conditional number. We found that the young ants mostly reacted to the small amount set on the left of a larger one as well as to the large amount set on the right of a smaller one, and this only in the presence of the non-conditional amount between the two conditional amounts. Thus, the young ants showed to possess a simple, concrete number representation of amounts on a left to right oriented scale. This number line is thus present in ants early after their emergence from the nymph stage.

Let us here make a few remarks on the present experimental work. We did not use numerosity larger than 5 because the ants' discrimination between two numbers quickly decreases with the relative difference between these numbers (Cammaerts \& Cammaerts, 2020). We performed no more experiments here because we wanted to soon use the same young ants for a next study before they could have learned and acquitted some significant experience. Knowing that they learn by imitating older nestmates (Cammaerts, 2013), we maintained them in their own small nests, isolated from any contact with older workers.

Though being beyond the subject of the present work, it may be interesting to recall how the ant $M$. sabuleti acquires some of its capabilities (Cammaerts \& Cammaerts, 2015 and references therein). Nest and congeners' odors are memorized during the larval life, by habituation. The visual aspect of the front part of congeners is learned instantaneously by imprinting at the emergence, which occurs with the help of at least one congener. The odor of the nest entrance is learned thanks to imprinting when experienced for the first time, and its visual aspect is progressively memorized over successive going out and in the nest. The foraging area odor is memorized by imprinting when coming for the first time on that area. Alarm behavior and trail following behavior are learned progressively and such learning is facilitated by the presence of older congeners exhibiting these behaviors, the young ant using imitation at the start of learning (Cammaerts, 2013). The present work completes thus these studies: the ants appear to natively possess a left to right oriented number line. A following work should investigate the acquisition of the notion of zero by ants.

Possessing a native number line was found in a few other species already studied as for this topic. For example, three to four-day old domestic chicks show a rightward bias when they search for the larger number of objects after having sighted two displayed amounts (Rugani et al., 2014), and indeed they situate smaller amounts on their left and larger amounts on their right, having natively a mental left to right number line (Rugani et al., 2015). Spontaneously also, i.e. without having been trained, rhesus monkeys arrange amounts on a scale (Hauser et al., 2000; Flombaum et al., 2005). Great apes, like gorillas and orangutans, which had no preexisting representation organizing the domain in which they were tested showed performance consistent with the magnitude and distance effects, conform to Weber's law, i.e. a faster and higher accurate response with larger ratios between quantities, a characteristic accounting for a mental compressed number line. However, depending to the individual tested, their response varied as for the direction of the oriented number line (Gazes, Diamond, Hope, Caillaud, Stoinski, \& Hampton, 2017), an idiosyncrasy of response also found in preschool human infants with limited cultural experience (Shaki, Fischer, \& Göbel, 2012).

The onset of a number line has been more thoroughly investigated in humans. Children in their $5^{\text {th }}$ or $6^{\text {th }}$ year have an elementary sense of numbers and make approximate non-symbolic arithmetic prior being instructed to it (Barth, Beckmann, \& Spelke, 2008). As shown by a line-bisection task, a mental number line connecting numerical and spatial representations is detained by adult humans as well as by young children well before their instruction (de Hevia \& Spelke, 2009). Already at the age of 7-8 months, thus prior to experience with language, symbolism and 
measurement, infants spontaneously show a predisposition to relate numerical magnitude to spatial length, which is the essence of a mental number line (de Hevia \& Spelke, 2010). Even neonates were shown to relate number and duration to spatial length when these dimensions varied in the same direction, however not when in opposite directions (de Hevia, Izard, Coubart, Spelke, \& Streri, 2014). At the age of 7 months, infants spontaneously prefer increasing numerical sequences than decreasing ones displayed in a left to right spatial orientation, as well as decreasing sequences than increasing ones under the reverse orientation (de Hevia, Girelli, Addabbo, \& Cassia, 2014). Preschool children, 3- to 5-year old, intuitively relate numbers and length, doing so more efficiently than with other variables such as brightness (de Hevia, Vanderslice, \& Spelke, 2012). Humans have thus a spontaneous tendency to represent numbers on a number line. However, there is plasticity in the shaping of the number line, as preschool 3- and 4-year-old children can be induced to associate number and space according to directional oriented training (Patro, Fischer, Nuerk, \& Cress, 2015). The precision of the preschool early ability in representing amounts on a number line predicts later mathematical performance (Mazzocco, Feigenson, \& Halberda, 2011).

The humans' innate possession of a number line is validated by the consequence of two health impairments. Brain damage (hemispatial neglect) affects the representation of numbers on the mental number line (Zorzi, Priftis, \& Umiltà, 2002). Children with normal intelligence, but having difficulties when starting to learn simple mathematical operations (i.e. suffering from dyscalculia) appear to be deficient as for the possession of a number line, which should thus be natively detained or at least very early acquired. Such children are treated thanks to particular training program and make progress in mathematical learning in the course of their acquisition of the number line (Kucian et al., 2011).

In humans, number mapping initially appears to be intuitively logarithmic as shown by indigene people having no formal education. However, after being educated, a shift takes place towards a linear mapping (Dehaene, Izard, Spelke, \& Pica, 2008). Such a shift from logarithmic to linear representation of numerical magnitudes was followed in infants in the course of their educational course (Laski \& Siegler, 2007; Siegler, Thompson, \& Opfer, 2009). Their acquisition of a precise number representation is 'a mental revolution, unique to Homo sapiens' and is the first step on the way to higher mathematics (Dehaene, 2011, p. 260).

The question of the origin and the acquisition of numerosity competences is a full expanding research domain which has much to learn to us. As an example, when comparing unschooled Yupno Papuan New Guinea indigenes and undergraduate Americans, it was found that the Papuan participants spontaneously favored spatial grouping of items over an oriented linear ordering that they used in a not consistent way, while culturally regimented Americans favored rightward linear oriented ordering. Thus, at least as it concerns humans, linear ordering may not be the only native way of ordering items and the origin of ordering may perhaps lie in experiential natural situations (Cooperrider, Marghetis, \& Núñez, 2017).

Returning to the ants, having a mental clear representation of numbers or amounts on a line is likely to facilitate their counting or subitizing of amounts over their daily social tasks, such as evaluating their walked distance, counting cues encountered while navigating, counting their turns, assessing the number of antennal strokes exchanged with nestmates, and choosing food sites containing the larger amount of food.

\section{Conflict of interests}

The authors declare that there is no conflict of interests regarding the publication of this paper.

\section{References}

Agrillo, C., Dadda, M., Serena, G., \& Bisazza, A. (2008). Do fish count? Spontaneous discrimination in female mosquitofish. Animal Cognition, 11, 495-503.

Agrillo, C., Piffer, L., Bisazza, A., \& Butterworth, B. (2012). Evidence for two numerical systems that are similar in humans and guppies. PLoSONE, 7(2), e31923.

Barth, H., Beckmann, L., \& Spelke, E. (2008). Nonsymbolic, approximate arithmetic in children: Evidence for abstract addition prior to instruction. Developmental Psychology Journal, 44(5), 1466-1477.

Buckingham, J. N., Wong, B. B. M., \& Rosenthal, G. G. (2007). Shoaling decisions in female swordtails: How do fish gauge group size? Behaviour, 144(11), 1333-1346.

Cammaerts, M.-C. (2013). Sensu stricto individual conditioning, and imitation, in the ant Myrmica sabuleti (Hymenoptera, Formicidae). Annales de la société entomologique de France, 49, 402-412.

Cammaerts, M.-C., \& Cammaerts, R. (2015). Ontogenesis of ants' cognitive abilities (Hymenoptera, Formicidae). Advanced Studies in Biology, 7, 335-348 + synopsis: 349-350. 
Cammaerts, M.-C., \& Cammaerts, R. (2019). Left to right oriented number scaling in an ant. International Journal of Biology, 11(4), 67-79.

Cammaerts, R., \& Cammaerts, M.-C. (2020). Ants' mental positioning of amounts on a number line. International Journal of Biology, 12(1), 30-45.

Cooperrider, K., Marghetis, T., \& Núñez, R. (2017). Where does the ordered line come from? Evidence from a culture of Papua New Guinea. Psychological Sciences, 28, 599-608.

De Hevia, M.-D., \& Spelke, E. S. (2009). Spontaneous mapping of number and space in adults and young children. Cognition, 110, 198-207.

De Hevia, M.-D., \& Spelke, E. S. (2010). Number-space mapping in human infants. Psychological Science, 21(5), 653-660.

De Hevia, M.-D., Girelli, L., Addabbo, M., \& Cassia, V. M. (2014). Human infants' preference for left-to-right oriented increasing numerical sequences. PLoS ONE, 9(5), e96412.

De Hevia, M.-D., Izard, V., Coubart, A., Spelke, E. S., \& Streri, A. (2014). Representations of space, time, and number in neonates. PNAS, 111(13), 4809-4813.

De Hevia, M.-D., Vanderslice, M., \& Spelke, E. S. (2012). Cross-dimensional mapping of number, length and brightness by preschool children. PloS ONE, 7(4), e35530.

Dehaene, S. (2011). The Number Sense. New York, Oxford, University Press. Retrieved from https://psycnet.apa.org/record/2011-10610-000

Dehaene, S., Izard, V., Spzelke, E., \& Pica, P. (2008). Log or linear? Distinct intuitions of the number scale in Western and Amazonian cultures. Science, 320, 1217-1220.

Flombaum, J. I., Junge, J. A., \& Hauser, M. D. (2005). Rhesus monkeys (Macaca mulatta) spontaneously compute addition operations over large numbers. Cognition, 97, 315-325.

Gazes, R. P., Diamond, R. F., Hope, J. M., Caillaud, D., Stoinski, T. S., \& Hampton, R. R. (2017). Spatial representation of magnitude in gorillas and orangutans. Cognition, 168, 312-319.

Göbel, S. M., Shaki, S., \& Fischer, M. H. (2011). The cultural number line: A review of cultural and linguistic influences on the development of number processing. Journal of Cross-Cultural Psychology, 42(4), 543-565.

Hauser, M. D., Carey, S., \& Hauser, L. B. (2000). Spontaneous number representation in semi-free-ranging rhesus monkeys. Proceedings of the Royal Society of London B: Biological Sciences, 26(1445), 829-833.

Kucian, K., Grond, U., Rotzer, S., Henzi, B., Schonmann, C., Plangger, F., ..., \& von Aster, M. (2011). Mental number line training in children with developmental dyscalculia. NeuroImage, 57(3), 782-795.

Laski, E. V., \& Siegler, R. S. (2007). Is 27 a big number? Correlational and causal connections among numerical categorization, number line estimation, and numerical magnitude comparison. Child Development, 78(6), 1723-1743.

Mazzocco, M. M., Feigenson, L., \& Halberda, J. (2011). Preschoolers' precision of the approximate number system predicts later school mathematics performance. PLoS One 6, e23749.

Meyer, S. (2015). L'estimation numérique dans les apprentissages mathématiques: Rôles et intérêts de la mise en correspondance des représentations numériques au niveau développemental, éducatif et rééducatif. Education, Université Charles de Gaulle - Lille III.

Patro, K., Fischer, U., Nuerk, H.-C., \& Cress, U. (2015). How to rapidly construct a spatial-numerical representation in preliterate children (at least temporarily). Developmental Science, 19(1), 126-144.

Rugani, R., \& de Hevia, M.-D. (2017). Number-space associations without language: Evidence from preverbal human infants and non-human animal species. Psychonomic Bulletin \& Review, 24(2), 352-369. Retrieved from https://link.springer.com/article/10.3758/s13423-016-1126-2

Rugani, R., Rosa-Salva, O., \& Regolin, L. (2014). Lateralized mechanisms for encoding of object. Behavioral evidence from an animal model: The domestic chick (Gallus gallus). Frontiers in Psychology, 5(150),1-8.

Rugani, R., Vallortigara, G., Priftis, K., \& Regolin, L. (2015). Number-space mapping in the newborn chick resembles humans' mental number line. Science, 347(6221), 534-536. 
Shaki, S., Fischer, M. H., \& Göbel, S. M. (2012). Direction counts: A comparative study of spatially directional counting biases in cultures with different reading directions. Journal of Experimental Child Psychology, 112 , 275-281.

Siegel, S., \& Castellan, N. J. (1989). Nonparametric statistics for the behavioural sciences. Singapore, McGrawHill Book Company. Retrieved from https://www.amazon.com/Sidney-Siegel...Statistics... /B008WDIR6

Siegler, R. S., Thompson, C. A., \& Opfer, J. E. (2009). The logarithmic-to-linear shift: one learning sequence, many tasks, many time scales. Mind Brain Education, 3, 143-150.

Zorzi, M., Priftis, K., \& Umiltà, C. (2002). Brain damage: Neglect disrupts the mental number line. Nature, 417 , 138-139.

\section{Copyrights}

Copyright for this article is retained by the author(s), with first publication rights granted to the journal.

This is an open-access article distributed under the terms and conditions of the Creative Commons Attribution license (http://creativecommons.org/licenses/by/4.0/). 